\title{
First Comprehensive Entomological Surveillance of Mosquitoes in Central Iran with Focus on Invasive Species
}

\section{Fatemeh Abedi-Astaneh ${ }^{1}$, Asghar Talbalaghi ${ }^{2,3 *}$, Mohammad Nikpour ${ }^{1}$, Ali Abbasi ${ }^{1}$, Mostafa Abdollahi ${ }^{1}$, Mohammad Javad Bagheri $^{1}$, Mohammad Elmifard ${ }^{1}$, Taher Orooji ${ }^{1}$ and Ahmad Oveis ${ }^{1}$}

${ }^{1}$ Deputy for Health, Qom University of Medical Sciences, Qom, Iran

${ }^{2}$ Freelance Consultant Deputy for Health, Qom University of Medical Sciences, Qom, Iran

${ }^{3}$ Founder of Italian Mosquito Control Association, Italy

*Corresponding Author: Asghar Talbalaghi, Freelance Consultant Deputy for Health, Qom University of Medical Sciences, Qom, Iran and Founder of Italian Mosquito Control Association, Italy.
Received: July 24, 2020

Published: September 25, 2020

(C) All rights are reserved by Asghar

Talbalaghi., et al.

\section{Abstract}

Mosquitoes are well-known vectors of some medically important diseases worldwide. Vector-borne diseases (VBD) account for $17 \%$ of all infectious diseases and more than $90 \%$ of the world's population is at risk of vector-borne diseases. Monitoring of mosquito populations is essential prior to the implementation of any population management strategies. According to the recommendations of international health authorities, such as the World Health Organization, the standard design for collection of adult mosquitoes is a key operation to address the issue of VBD. In view of the incidence of Zika, Chikungunya and Dengue Fever epidemics in countries neighboring Iran and tackle the occurrence threat of VBD, a surveillance action was implemented in the Province of Qom, Iran, in line with the actions of local law enforcement authorities; the city of Qom is, the holy city of the Shiite religion and is rich in sacred places, such as the sanctuary of Bibi Fatima Masoumeh and the Holy Mosque of Jamkaran. It is characterized by the presence of pilgrims of different ethnic backgrounds from Iran as well as from over 100 countries world-wide. The city of Qom (Figure 1) acts as crossroads for the country, and can be at risk of transmission of mosquito-vectored diseases. Considering the risk of transmission of the abovementioned diseases, in addition to West Nile Virus, not transmitted by Aedes mosquitoes, a qualitative entomological investigation of all mosquito species, including the invasive species, Aedes albopictus and Aedes aegypti, was conducted.

One of the outcomes of this study was cooperation and scientific contribution of the two countries, Iran and Italy, on the population management strategies of Aedes albopictus. Rather extensive Italian experience was carefully utilized in designing the current scientific work concluding in publication of a manual in Farsi as well as in Italian languages entitled, "Lessons Learned from Rome to Qom in the Study of Aedes". Until now Iran has not been seriously considered at the risk of invasive mosquito species and the present study will be of help in the population management in the event of eventual establishment of invasive mosquito vector species. This contribution provides information concerning early and rather broad entomological surveillance conducted on mosquito populations in central Iran and on the risk of related VBD. During the 28 weeks of a field collecting campaign, a total of 83,414 adult mosquitoes were collected. During the investigation, no invasive mosquito species were recorded. There was a total of 15 mosquito species belonging to 5 genera in the collections. In addition to mosquitoes, 933 specimens of sandflies were also collected which were initially not the objective of the study. The field-collected mosquito data were analyzed using GIS and SPSS.

Keywords: Mosquitoes; Trapping; Iran; Qom; VBD; Aedes albopictus; Aedes aegypti; Arboviruses; Entomological Surveillance 


\section{Introduction}

Mosquitoes are vectors of arboviruses affecting animals and human health [1]. Vector-borne diseases account for more than $17 \%$ of all infectious diseases, annually causing more than 700,000 deaths world-wide [2]. Diseases, such as Malaria, Zika, Chikungunya, Dengue Fever and West Nile Fever are a major health problem in the world and are transmitted by Culicidae mosquitoes [3].

Every year, malaria alone, transmitted by Anopheles spp. mosquitoes, kills 400,000 people (mainly children) and incapacitates another 200 million for days [4]. Knowing where vector mosquito species occur is crucial for the assessment of vector-borne disease risk [5]. There are three subfamilies of mosquitoes in the family Culicidae including Anophelinae, Culicinae and Toxorhynchites [6]. Among members of these subfamilies, some are main vectors of disease organisms while others are secondary vectors [7]. For instance, Culex quinquefasciatus is not only the main vector of West Nile fever virus, but is also secondary vector for the transmission of arboviruses [8]. The extensive outbreak of Chikungunya in the Indian Ocean region during 2005 - 2006 and its subsequent outbreak in the Emilia Romagna region of Italy in August 2007, necessitate prompt action without any delay to prevent any future recurrence of such outbreaks [9]. The ever-increasing world-wide movement of humans infected with mosquito-vectored parasites and pathogens and the climate change are conducive to increase the risk of new local transmission of mosquito-vectored disease organisms. In recent years, the rapidity of transportation of goods and humans from one part of the globe to another, compared to the past, allows unchecked entry of a variety of exotic insects as eggs, larvae and winged forms into the new territory [10]. Until recently, investigation on the occurrence of invasive mosquito?? species in Iran did not reveal any invasive species, except for the report of [11] who in 2009 had detected larvae of Ae. albopictus in the samples collected from the counties of Nikshahr and Sarbaz situated on the Southeast of Sistan and Baluchestan Provinces of Iran, close to the international border with Pakistan. Early surveillance of qualitative and quantitative compositions of mosquito populations in urban and rural areas of Qom Province since 2018 is a key step prior to the permanent establishment of any invasive mosquito species in the territory of Qom Province. This work is an activity that we focus on, is as a valid approach of surveillance for the implementation of a valid strategy for vector control, when the establishment of invasive mosquitoes is a realty. The main objective of this mosquito research can be summarized that: through an accurate and extensive monitoring we could say, where are the mosquitoes are coming from [12].

\section{Materials and Methods}

Study area

The Province of Qom is one of the 31 provinces of Iran. It has an extension of $11,238 \mathrm{~km}^{2}$ covering $0.68 \%$ of the total area of Iran (Figure 1) and is located in the center of the country. is located in a plain at an altitude of $900 \mathrm{~m}$ above sea level. The capital of province is the city of Qom. laying. Qom has a total population of approximately1,350,000. Of this total, $94 \%$ of the population resides in urban areas and the rest is necessary in rural vicinities. The province consists of one city, five counties, nine rural districts, and 185 villages. The climate of Qom province varies between a desert and semi-desert climate; the province comprises of mountainous areas, foothills and plains. Due to its location near an arid region and far inland, it experiences a dry climate, with low humidity and scanty rainfall. Thus, agriculture is not possible in most of its area, especially near the Salt Lake regions. During the present study, in 2018, the reported lowest and highest temperatures in Qom province were 3.3 and $45.5^{\circ} \mathrm{C}$ in April and June, respectively. During this period, the recorded lowest and highest relative humidity was $4 \%$ in September and $98 \%$ in April. The mean rainfall during this investigation was $0.15 \mathrm{~mm}$. The lowest solarium and the highest solarium in Qom province was reported as 0.0 hour in April and 13.1 hours in July. During this period, $85 \%$ of days were without rain.

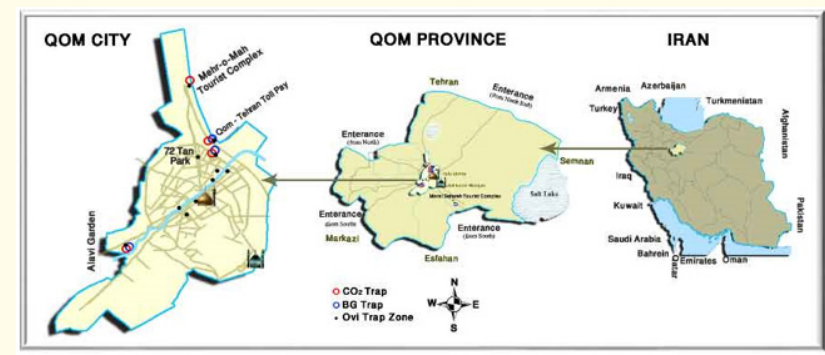

Figure 1: Map of the study area, Qom Province, Iran, 2018.

\section{Collection of Culicidae mosquitoes}

The main purpose of this study was to investigate the presence of Ae. albopictus and Ae. aegypti mosquitoes. Any monitoring of these species is usually based on the presence of their eggs by use of special ovitraps. For this purpose, 200 ovitraps in 9 different zones (Black pin in figure 1) were installed and examined on daily 
basis or weekly basis??? for the presence of their eggs. Since there is no previous record of the presence of these invasive species in the country, adult monitoring was also required by setting up BG Sentinel traps. According to our knowledge, this is the first attempt for monitoring Ae. albopictus and Ae. egypti species in Iran. If eggs of these species were found, that would mean that the invasive species had already entered the country prior to the egg monitoring by using ovitraps. Thus, the use of adult monitoring by use of BG traps was necessary. Mosquito collection was conducted using 3 types of traps by 16 field technicians during March 2018 to October 2018. The traps were placed at the rest areas and parks and at the entrance to the Qom province. Eight traps (4 BG traps and $4 \mathrm{CO}_{2}$ traps) for monitoring adult mosquitoes, and 200 ovitraps for collecting eggs of Aedes were setup. Traps were installed and checked for four 4 days in a week. The daily observation activity was rotated, for example, from Saturday to Wednesday in the first week and from Sunday to Thursday in the second week, etc (Table 1). The province of Qom remains very hot and dry during the summer months and very cold during the winter months. The invasive mosquito species eventually reached Qom, probably transported passively from areas where they initially were already established by various means of transportation of goods and people. Adults and eggs adapt to new unfavorable areas choosing cooler environments during summer and warmer during the winter. Therefore, during monitoring, 53 ovitraps were installed at different locations in the Province of Qom from $1 \mathrm{~m}$ to $5 \mathrm{~m}$ subsurface considered as favorable zones of their occurrence. In this regard, attention was paid to less hostile climate in the observation territory and the ovitraps were lowered below ground level with a string, in water wells and sewage man holes where usually milder temperatures prevail, while protecting the traps from wind action and simultaneously providing shadow preferred by the invasive species (Figure 2).

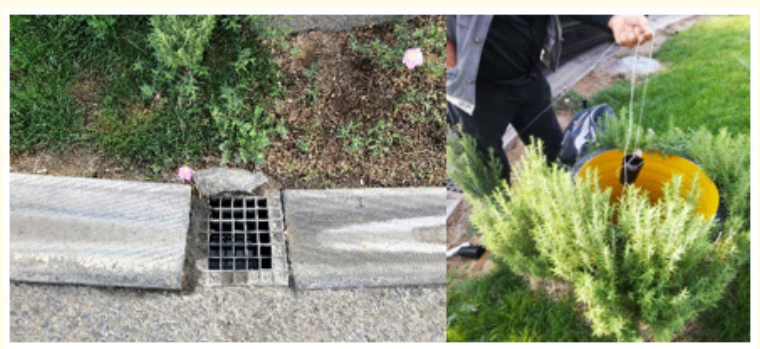

Figure 2: Monitoring invasive mosquitoes in hot and cold seasons.

\begin{tabular}{|c|c|c|c|}
\hline $\begin{array}{l}\text { Number and } \\
\text { day of the week }\end{array}$ & & Time of the day & Activity \\
\hline \multirow{2}{*}{ First } & \multirow{2}{*}{ Saturday } & Morning & Throughout of BG Trap \\
\hline & & Evening & Gather the net of BG Trap and Installation of $\mathrm{CO}_{2}$ Trap \\
\hline \multirow{2}{*}{ Second } & \multirow{2}{*}{ Sunday } & Morning & Gather the net of $\mathrm{CO}_{2}$ Trap and Installation of BG Trap \\
\hline & & Evening & Gather the net of BG Trap and Installation of $\mathrm{CO}_{2}$ Trap \\
\hline \multirow{2}{*}{ Third } & \multirow{2}{*}{ Monday } & Morning & Gather the net of $\mathrm{CO}_{2}$ Trap and Installation of BG Trap \\
\hline & & Evening & Gather the net of BG Trap and Installation of $\mathrm{CO}_{2}$ Trap \\
\hline \multirow{2}{*}{ Forth } & \multirow{2}{*}{ Tuesday } & Morning & Gather the net of $\mathrm{CO}_{2}$ Trap and Installation of BG Trap \\
\hline & & Evening & Gather the net of BG Trap and Installation of $\mathrm{CO}_{2}$ Trap \\
\hline \multirow{2}{*}{ Fifth } & \multirow{2}{*}{ Wednesday } & Morning & Gather the net of $\mathrm{CO}_{2}$ Trap \\
\hline & & Evening & Off \\
\hline Sixth & Thursday & $\begin{array}{l}\text { Morning and } \\
\text { Evening }\end{array}$ & Off \\
\hline \multirow{2}{*}{ Seventh } & \multirow{2}{*}{ Friday } & Morning & Installation of BG Trap \\
\hline & & Evening & Gather the net of BG Trap and Installation of $\mathrm{CO}_{2}$ Trap \\
\hline Continues & & & \\
\hline
\end{tabular}

Table 1: Plan of daily activity. 
The BG Trap is tailor-made for collection of Aedes albopictus adults. In this trap, Synthetic odours are used to attract invasive adult mosquitoes. The traps are installed before sunrise and dismounted half an hour before sunset (Figure 3).

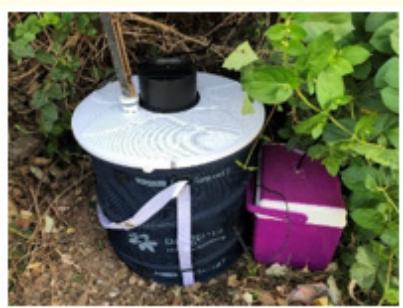

Figure 3: BG Trap.

The $\mathrm{CO}_{2}$ traps were installed half dismounted before sunrise of the following day. In $\mathrm{CO}_{2}$ traps, light was used as an additional adult mosquitoes attractant (Figure 4).

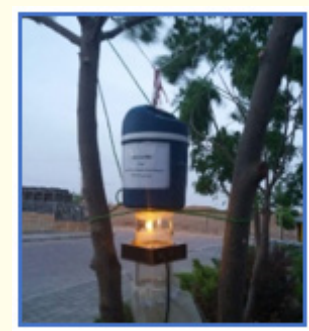

Figure 4: $\mathrm{CO}_{2}$ Trap.

Nine separate ecological zones were identified for the field placement of 200 ovitraps in the Qom province (Figure 5). A majority of the ovitraps were placed in Qom city. The ovitraps were used with the purpose of collecting eggs of Aedes species. Permanent placement sites of these traps included the entry roads to Qom from the north, northwest, and northeast of the country, in the Mehr-o-Mah rest area and tourist complex (one $\mathrm{CO}_{2}$ trap and 15 ovitraps), the Qom-Tehran toll plaza (one $\mathrm{CO}_{2}$ trap, one BG trap and 20 ovitraps), the 72 Tan Park (one $\mathrm{CO}_{2}$ trap, one BG trap and 30 ovitraps) and at the Qom road entrances from southern, south western and southeastern areas of the country in the Maral Setareh tourist complex (one BG trap and 15 ovitraps), the Alavi Garden (one BG trap, one $\mathrm{CO}_{2}$ trap and 20 ovitraps). Around the Holey shrine of Masoumeh, around the Qom river, around the assigned bus terminals where pilgrims arrive from neighboring countries that had VBD epidemic situation, at car terminals for Karbala and Najaf pilgrimage, Mersad Park, Hashemi garden, the Qom-Kashan toll Pay were the further locations of ovitraps placement. Geographic coordinates for the sampling sites were determined by using a Global Positioning System (GPS) device. The captured Culicidae mosquitoes were placed in the refrigerator for 5 - 10 minutes. The Culicidae mosquitoes were morphologically identified within 1-2 hours and some of them were selected as pool and kept in nitrogen tank for further investigation of arboviruses. All mosquitoes were identified using the relevant morphological keys and 40X stereomicroscope lens.

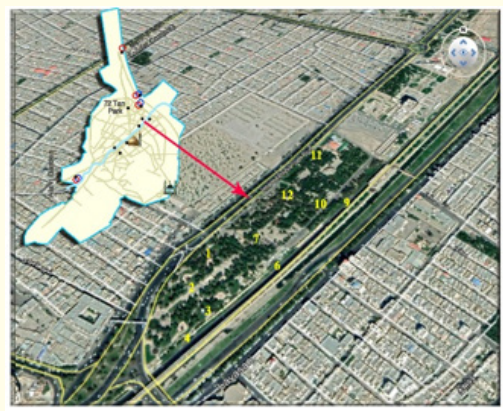

Figure 5: Station of Ovitrap.

Prevailing weather data

Updated weather data including air temperature (maximum, minimum), relative humidity (maximum, minimum), rainfall, solarium, wind speed direction were obtained from Qom Meteorological Organization for the weather station of the Qom province. Vegetation cover, vicinity of water bodies and density of human population to mosquito occurrence were ranked at selected stations. Detailed data on altitude were obtained from GIS Department of Qom Governorate.

\section{Data on Multi-state variables}

Multi-state variables, such as density of human population, vegetation cover, immediate vicinity of water bodies and wind direction were leveled by intuition. Density of human population was ranked into 3 categories, Vegetation cover was ranked into 4 categories, immediate vicinity of water bodies was ranked into 4 categories and wind direction was ranked into 8 categories (NorthNortheast "0-45”, Northeast "46-90 ”, Southeast"91-135”, SouthSoutheast "136-180" " and North-Northwest"181-225”", Northwest “226-270”, Southwest“271-315”, South-Southwest“316-380”) (Figure 6-10). 


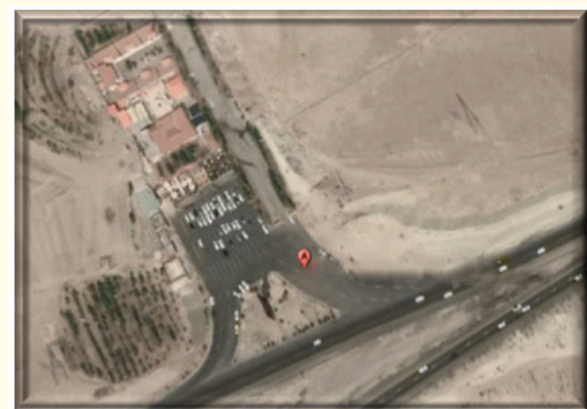

Figure 6: Rest area Maral Setareh tourist complex: Density of human population $=1$, Vegetation cover $=1$, Vicinity of water bodies $=1$.

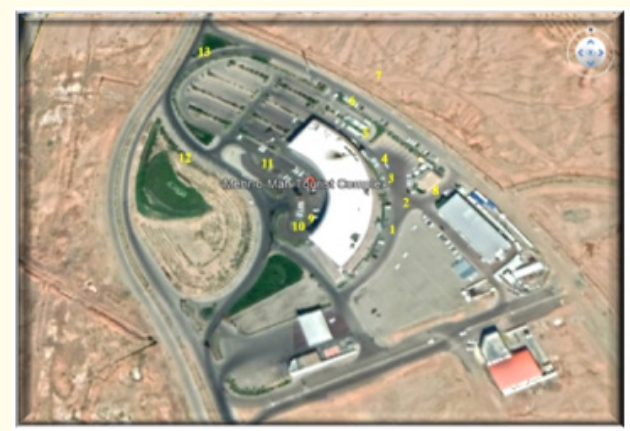

Figure 7: Rest area Mehr-o-Mah tourist complex: Density of human population $=1$, Vegetation cover $=1$, Vicinity of water bodies to mosquitoes $=2$.

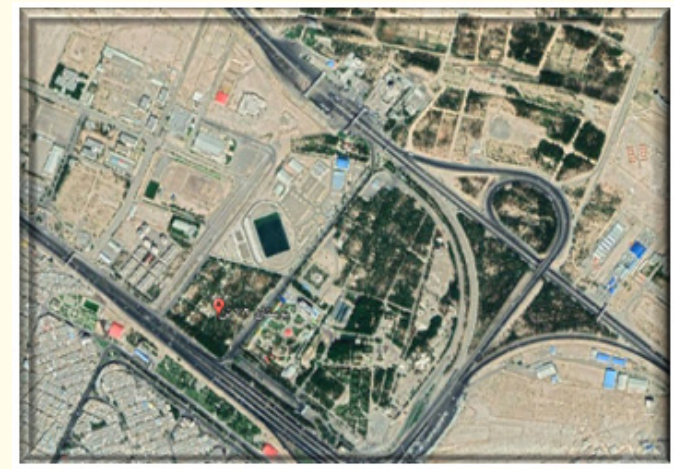

Figure 8: Rest area 72 Tan Park: Density of human population $=3$, Vegetation cover $=3$, Vicinity of water bodies $=2$.

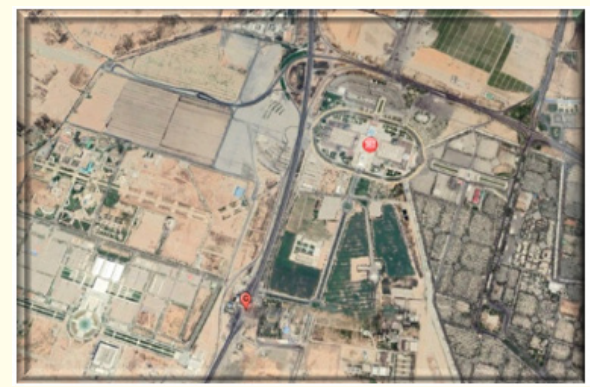

Figure 9: Alavi Garden: Density of human population $=4$. Vegetation cover $=3$, Vicinity of water bodies $=2$.

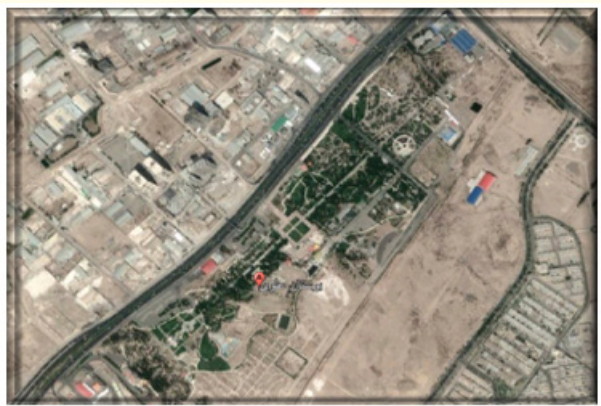

Figure 10: Qom- Tehran toll pay: Density of human population $=3$, Vegetation cover $=2$, Vicinity of water bodies $=4$.

\section{Data analysis}

The collected data concerning Culicidae mosquitoes, sandflies, and houseflies were transferred to an excel sheet and then converted to the shape file of spatial distribution of Culicidae in ArcMap. This information was also analyzed using SPSS.

\section{Results}

The total number of adult mosquitoes caught amounted to 84,743 , including Culicidae mosquitoes $(83,414)$, Some sandflies (933) and houseflies (396) also occurred in the collections. All collected Culicidae were identified as Culex genera, CX. pipiens, $C x . v a-$ gans, Cx. theileri, Cx. territans, Cx. martinii, and Cx. hortensis. The collected species of Aedes mosquitoes were Ae. caspius, Ae. dorsalis, Ae. excrucians, and Ae. rustica), while the species of Culiseta were Cu. annuleta, Cu. subochrea, Cu. litorea, Cu. logioareolata, and $\mathrm{Cu}$. Fumipennis. In addition Anopheles and Uranotaenia mosquitoes 
were collected (Table 2). The most abundant mosquito genus was Culex (94.6\%), followed by Culiseta (1.9\%), Uranotaenia (1.8\%), Aedes (1.2\%), and Anopheles (0.002\%) (Figure 11). Some mosquito that could not be identified to species with available taxonomic keys were identified in the laboratory using molecular techniques. In this study, Ae. albopictus and Ae. aegypti did not occur. The highest mosquito catch was during June (Figure 12-16). It seems that $\mathrm{CO}_{2}$ traps were more efficient since the collections in them were higher in terms of numbers and species of mosquitoes. Both $\mathrm{CO}_{2}$ traps and BG traps are efficient to collect mosquitoes. Since most Culicidae are nocturnal in terms of activity, $\mathrm{CO}_{2}$ traps demonstrated the best performance. SPSS was used for entering data and analyzing variables, such as temperature and humidity (minimum, maximum and mean), wind (speed, direction), solarium, rainfall, vegetation cover of trap position, vicinity of water bodies and density of human population.

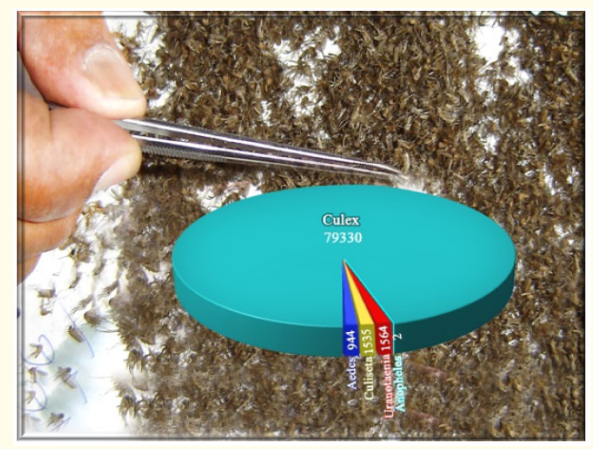

Figure 11: Composition of all Culicidae collected during the field activity, Qom Province, Iran, 2018.

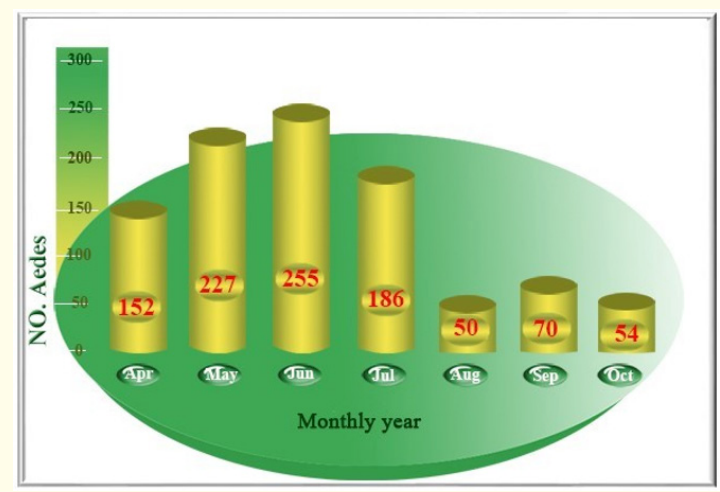

Figure 12: Monthly collection of Aedesspp.in the study areas, Qom Province, Iran, 2018.

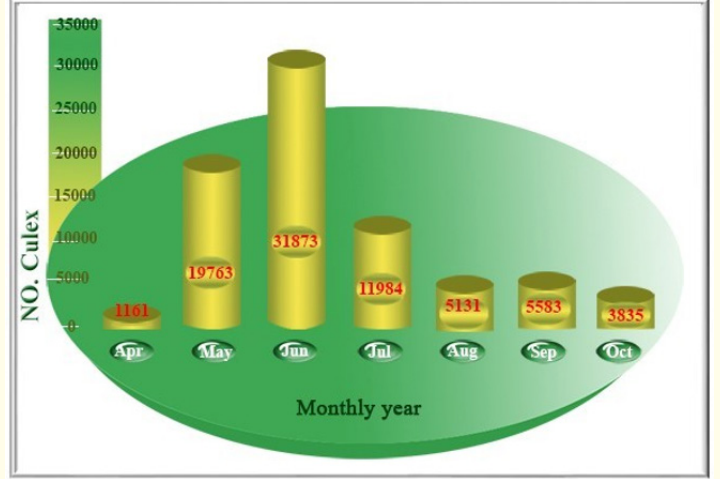

Figure 13: Monthly collection of Culex spp.in the study areas, Qom Province, Iran, 2018.

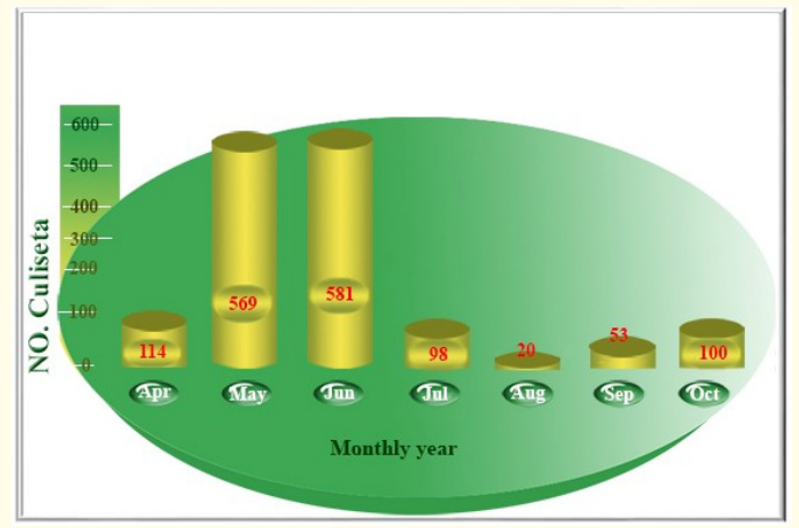

Figure 14

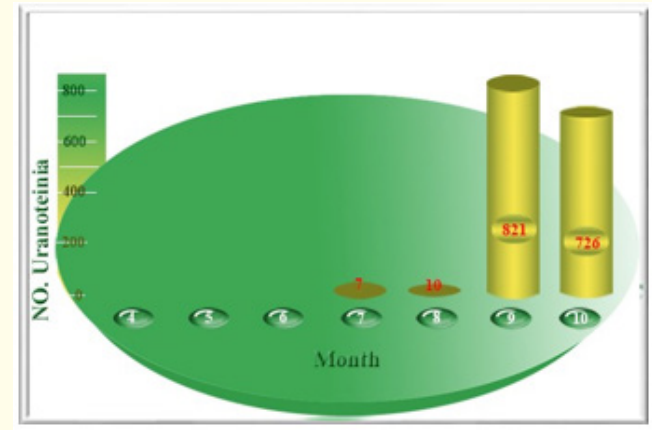

Figure 15: Monthly collection of Uranotaenia mosquitoes in the study areas, Qom Province, Iran, 2018 


\begin{tabular}{|c|c|c|c|c|c|c|c|c|c|c|c|c|c|c|c|c|c|c|c|c|c|c|c|c|c|}
\hline \multirow[b]{2}{*}{ 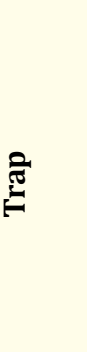 } & \multirow[b]{2}{*}{ 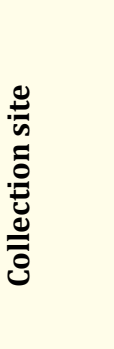 } & \multirow[b]{2}{*}{ 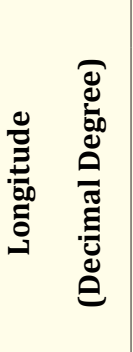 } & \multirow[b]{2}{*}{ 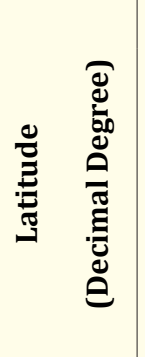 } & \multirow[b]{2}{*}{ 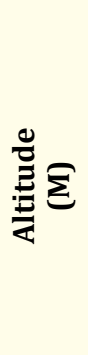 } & \multicolumn{19}{|c|}{ Culicidae } & \multirow[b]{2}{*}{ స్త్ర } & \multirow[b]{2}{*}{$\vec{x}$} \\
\hline & & & & & $\frac{2}{\tilde{a}}$ & 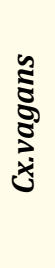 & $\begin{array}{l}\frac{1}{2} \\
\frac{\pi}{2} \\
\frac{\pi}{2}\end{array}$ & 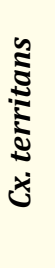 & 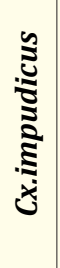 & 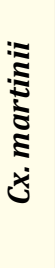 & $\frac{\mathscr{y}}{\tilde{y}}$ & 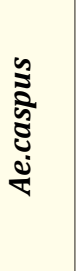 & 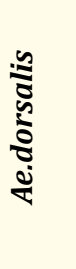 & 芯 & 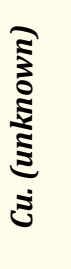 & 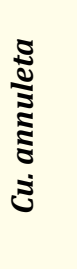 & 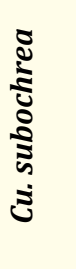 & 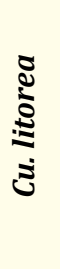 & 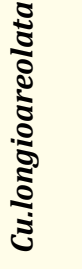 & & 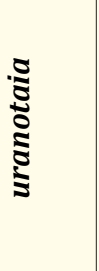 & $\begin{array}{c}\frac{\mathfrak{d}}{0} \\
\frac{\mathfrak{d}}{2} \\
\frac{1}{2}\end{array}$ & $\frac{0}{\Sigma}$ & & \\
\hline \multirow{5}{*}{$\begin{array}{l}\text { CO- } \\
{ }_{2} \text { Trap }\end{array}$} & $\begin{array}{c}\text { Mehr- } \\
\text { o-Mah } \\
\text { Tourist } \\
\text { Com- } \\
\text { plex }\end{array}$ & 50.8682 & 34.7423 & 895 & 2,269 & 1 & 32 & 1 & 0 & 15 & 0 & 586 & 91 & 0 & 30 & 224 & 181 & 4 & 34 & 1 & 0 & 0 & 3 & 34 & 2 \\
\hline & $\begin{array}{c}\text { Qom- } \\
\text { Tehran } \\
\text { Toll } \\
\text { Pay } \\
\end{array}$ & 50.8927 & 34.6859 & 924 & 7,1756 & 0 & 3 & 0 & 0 & 6 & 1 & 113 & 15 & 1 & 291 & 114 & 191 & 11 & 291 & 0 & 1,543 & 0 & 319 & 610 & 0 \\
\hline & $\begin{array}{c}72 \text { Tan } \\
\text { Park }\end{array}$ & 50.8919 & 34.6806 & 934 & 4,403 & 4 & 19 & 1 & 2 & 1 & 0 & 178 & 22 & 0 & 4 & 97 & 72 & 0 & 14 & 41 & 20 & 0 & 34 & 73 & 9 \\
\hline & $\begin{array}{c}\text { Alavi } \\
\text { Garden }\end{array}$ & 50.8161 & 34.5871 & 982 & 125 & 4 & 6 & 0 & 0 & 0 & 0 & 7 & 3 & 0 & 0 & 0 & 1 & 0 & 1 & 0 & 0 & 0 & 2 & 3 & 1 \\
\hline & $\begin{array}{c}\text { Mobile } \\
\text { sta- } \\
\text { tions }\end{array}$ & & & & 7 & 0 & 0 & 0 & 0 & 0 & 0 & 0 & 0 & 0 & 0 & 0 & 1 & 0 & 0 & 0 & 0 & 0 & 0 & 154 & 5 \\
\hline & & & \multicolumn{2}{|c|}{ Sum. $\mathrm{CO}_{2}$ Trap } & 78,560 & 9 & 60 & 2 & 2 & 22 & 1 & 884 & 131 & 1 & 325 & 435 & 446 & 15 & 340 & 42 & 1,563 & 0 & 358 & 874 & 17 \\
\hline \multirow{5}{*}{$\begin{array}{c}\text { BG } \\
\text { Trap }\end{array}$} & $\begin{array}{c}\text { Qom- } \\
\text { Tehran } \\
\text { Toll } \\
\text { Pay }\end{array}$ & 50.8907 & 34.6861 & 936 & 274 & 0 & 0 & 0 & 0 & 0 & 0 & 0 & 0 & 0 & 0 & 1 & 0 & 0 & 0 & 0 & 0 & 0 & 19 & 20 & 24 \\
\hline & $\begin{array}{c}72 \text { Tan } \\
\text { Park }\end{array}$ & 50.8915 & 34.6797 & 920 & 147 & 0 & 0 & 0 & 0 & 0 & 0 & 11 & 2 & 0 & 0 & 3 & 0 & 0 & 0 & 0 & 0 & 0 & 3 & 19 & 34 \\
\hline & $\begin{array}{c}\text { Maral } \\
\text { Se- } \\
\text { tareh } \\
\text { tourist } \\
\text { com- } \\
\text { plex }\end{array}$ & 51.091 & 34.4585 & 925 & 4 & 0 & 0 & 0 & 0 & 0 & 0 & 0 & 0 & 0 & 0 & 0 & 0 & 0 & 0 & 0 & 0 & 0 & 5 & 5 & 210 \\
\hline & $\begin{array}{c}\text { Alavi } \\
\text { Garden }\end{array}$ & 50.8158 & 34.5873 & 981 & 42 & 0 & 1 & 0 & 0 & 0 & 0 & 1 & 0 & 0 & 0 & 0 & 0 & 0 & 1 & 0 & 0 & 2 & 0 & 4 & 111 \\
\hline & $\begin{array}{c}\text { Mobile } \\
\text { sta- } \\
\text { tions }\end{array}$ & & & & 15 & 0 & 0 & 0 & 0 & 0 & 0 & 0 & 0 & 0 & 0 & 0 & 0 & 0 & 2 & 0 & 0 & 0 & 11 & 0 & 0 \\
\hline & & & \multicolumn{2}{|c|}{ Sum. BG Trap } & 482 & 0 & 1 & 0 & 0 & 0 & 0 & 12 & 2 & 0 & 0 & 4 & 0 & 0 & 3 & 0 & 0 & 2 & 38 & 59 & 379 \\
\hline & & & & Sum & 79,042 & 9 & 61 & 2 & 2 & 22 & 1 & 896 & 133 & 1 & 325 & 439 & 446 & 15 & 343 & 42 & 1563 & 2 & 70 & 933 & 396 \\
\hline & & & & $\begin{array}{l}\text { To- } \\
\text { tal }\end{array}$ & \multicolumn{19}{|c|}{83,414} & 933 & 396 \\
\hline
\end{tabular}

Table 2: Culicidae fauna in the study area collected by CO2 traps and BG traps at vaeious sites, Qom province, Iran, 2018. 


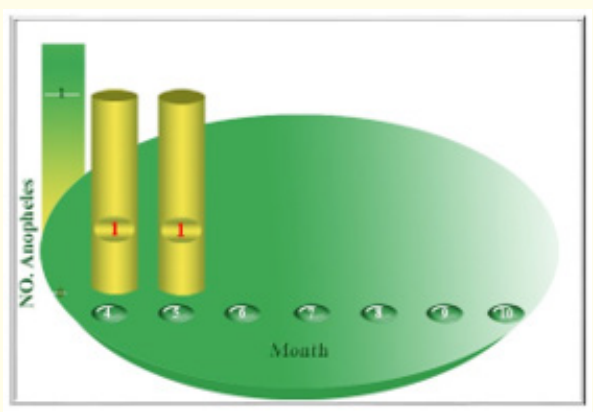

Figure 16: Monthly collection of Anopheles mosquitoes in the study areas, Qom Province, Iran, 2018.

Among the above-mentioned factors, the following information was obtained from the correlation analysis: all temperature indices (min, max and mean) $(\mathrm{P}<0.05)$ and windspeed $(\mathrm{P}=0.02)$ measurements had a significant effect on the abundance of collected Culex spp. All three temperature indices $(\mathrm{P}<0.05)$, rainfall $(\mathrm{P}=$ $0.002)$ and wind direction $(P=0.005)$ had a significant effect on the abundance of collected Culiseta and maximum temperature $(P=0.036)$ showed significant inverse effect. The only variable that had significant inverse effect on the abundance of collected Uranotaenia was relative humidity $(\mathrm{P}=0.03)$. No significant effect was observed by the "quantitative" variables on the abundance of collected species of Aedes and Anopheles mosquitoes, specifically Anopheles spp., perhaps because they were fewer in numbers. It was statistically analyzed (chi square test) to determine whether vegetation cover, presence of water bodies in the sampling vicinity as well as density of human population and wind direction significantly influenced.

The occurrence of many sand flies and flies within the samples were also recorded which may be matter for local faunistic studies.

The collection of Culicidae or not. The results revealed. that density of human population, vegetation cover, and presence of water bodies in the vicinity of traps location had significant effect on the collections while wind direction had significant $(\mathrm{P}=$ 0.049) effect on the collection of Culiseta. According to chi-square test, vegetation cover at the geographical collection position $(\mathrm{P}=$ $0.00)$, presence of water bodies in the collection vicinity $(P=0.00)$, and density of human population $(\mathrm{P}=0.00)$ affected the number of collected Aedes; vegetation cover ( $\mathrm{P}=0.00)$, water bodies in the vicinity affected $(\mathrm{P}=0.00)$ affected the number of collected
Culex; vegetation cover indices $(\mathrm{P}=0.00)$, existing water bodies in the sampling vicinity $(\mathrm{P}=0.00)$, density of human population $(P=0.00)$ and wind direction significantly $(P=0.00)$ affected the number of collected Culiseta and vegetation cover $(\mathrm{P}=0.05)$, presence of water bodies in the collection vicinity significantly $(\mathrm{P}=$ 0.014) affected the number of collected Uranotaenia. GIS map of dispersion of Culicidae in Qom province is given (Figure 17). The descriptive table of SPSS shows that the density of human population had significant effect on collected Aedes and Culex but the increased number of human population density had a deterrent effect on collected Aedes spp. In terms of entomological interpretation of the afore-mentioned observation, Aedes mosquitoes are very aggressive in their blood sucking activity and, therefore are mostly attracted to humans rather than to $\mathrm{CO}_{2}$-baited traps placed in afield location. Similar patterns explained for Aedes species, seems, could have inverse effect on the collection of Culiseta species. The highest catches of Aedes and Culex occurred in the presence of dominant winds in southeasterly, south and southwesterly directions. It seems that most of breeding sites of these mosquitoes were located in northwest, north and northeast of trap locations if it is considered that wind has a mechanical dispersal effect. The highest catches of Culiseta were taken in the northeast, east and southeasterly wind directions (Figure 18). The following variables had a significant effect on the collected or non-collected different Culicidae: on collected or non-collected Aedes: relative humidity $(\mathrm{P}=0.021)$; for Culex: minimum temperature $(\mathrm{P}=0.041)$, mean temperature $(\mathrm{P}=0.047)$ and wind speed $(\mathrm{P}=0.012)$; for Culiseta: maximum temperature $(\mathrm{P}=0.049)$, relative humidity $(\mathrm{P}=0.00)$ and wind speed $(\mathrm{P}=0.015)$, and for Uranotaenia, relative humidity (min, max and mean) $(\mathrm{P}<0.05)$.

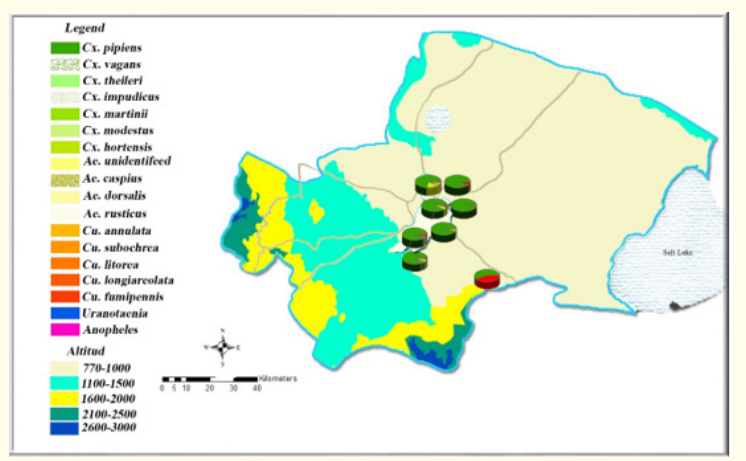

Figure 17: Geographical distribution of Culicidae collected in the study areas of Qom Province, Iran, 2018. 


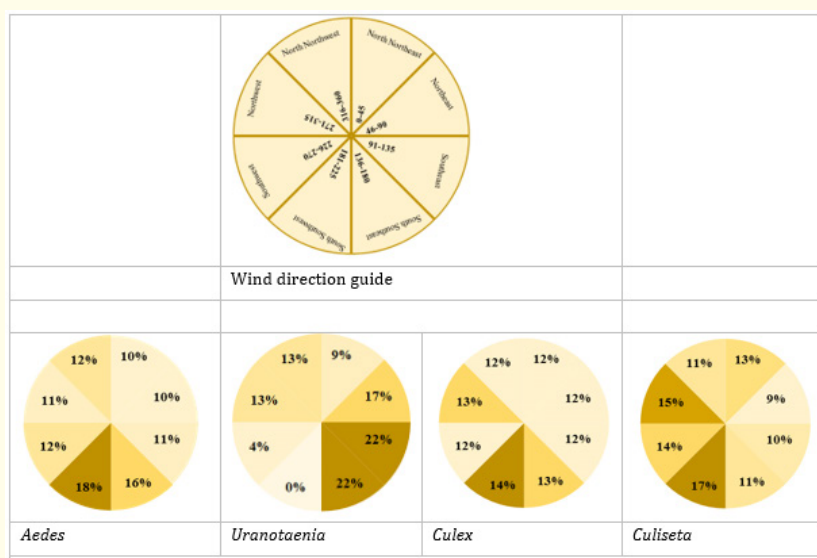

Figure 18: The percentage of days with collected mosquitoes under different wind directions during the study period, 2018.

\section{Discussion}

This field study is a scientific practical contribution for the field technicians and workers describing an innovative approach for entomological surveillance and has an outcome in the form of a guide addressed to all those who wish to try their hands in control of vector mosquitoes of diseases. For standard mosquito monitoring, the use of appropriate tools and traps are described. The large number of mosquito pools prepared during this activity primarily with the purpose of an ongoing investigation of pathogens, will be conducive to the creation of new knowledge concerning mosquito fauna in the Province of Qom, Iran, and will be helpful in formulation strategies to tackle the issues of mosquito vector-borne diseases. Large number of the adult of mosquitoes collected, come from the locations that have collected unevenly the mosquitoes, most of the mosquitoes are collected from the location, Qom- Tehran Toll Pay. The vicinity of a breeding site, created by an open sewage water body to the trap position is clearly conducive to many generations of Culex spp. As appears from figure 19, the rainfall during the (working weeks 1-2-3-4-5) to has been the cause of increased the collected mosquitoes. As is visible this rainfall has not influenced at all, the abundance of Uranotaenia (Figure 19).

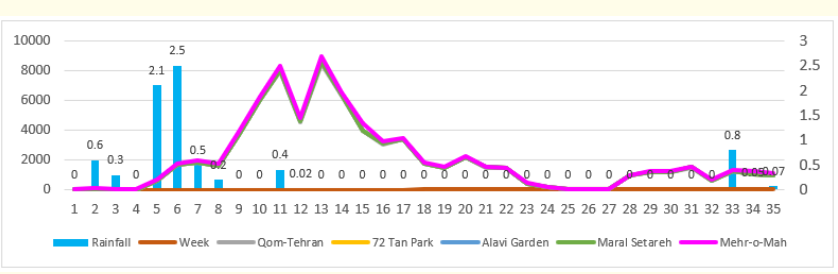

Figure 19: Relationship of total collected mosquitoes and rainfall during weeks of year* in the study areas, Qom Province, Iran, March to October, 2018.

* week 1= 31 March 2018 and week 35 = 11 October 2018.

\section{Conclusion}

The information on mosquito populations generated in this study allows the creation of a "Bank of Professional Information", on the diversity of mosquito species. This means that based on the generated data population management strategies of these mosquitoes can be developed and rooted locally to help the local organizations that deal with mosquito-related public health issues Early surveillance resulting from this database was the goal of this work. But to be used over the years, it must be constantly updated, from year to year. Moreover, this work and the bank of information created following this investigation, could facilitate similar approach to other vector-borne diseases of medical importance, such as sandflies, the vector of leishmanaisis and others.

\section{Acknowledgements}

The authors are grateful to the Managers and personnel of the Department of Health, Qom University of Medical Sciences, for their immense contributions and kind help in the field work. Gratitude is also expressed to Qom municipalities, Qom Parks and Greenery Organization, Qom Handicrafts, Tourism Organization and Ahle Beit Mosque. This research investigation is registered at Qom University of Medical Sciences under code no. 97959.

\section{Bibliography}

1. Sara Moutailler., et al. "A new high-throughput tool to screen mosquito-borne viruses in Zika virus endemic/epidemic areas". medRxiv (2019).

2. "Vector-borne diseases".

3. (WHO,2017).

4. Stockholm and Parma. Technical Report The importance of vector abundance and seasonality (C) European Centre for Disease Prevention and Control (2018).

5. The Barcelona Institute for Global Health (ISGlobal).

6. Arif Mehmood., et al. "Systematics of Anopheles and Armigerus (Culicidae: Diptera) mosquitoes in the Pothwar Region, Punjab, Pakistan". International Journal of Mosquito Research 3.5 .

7. A Talbalaghi., et al. "Are Aedes albopictus or other mosquito species from northern Italy competent to sustain new arboviral outbreaks?" Medical and Veterinary Entomology 24 (2010): 83-87.

8. Xiao-xia Guo., et al. "Culex pipiens quinquefasciatus: a potential vector to transmit Zika virus". Emerging Microbes and Infections (2016).

9. Source PubMed from Parassitologia 50 (2008): 125-126. 
10. Zanzare: "Postine":Senza confine ( mosquitoes, vectors without border, which travel ticketless by trains), Speciale "Parchi di Piemonte". Journal of Piedmont Regional Government (2012).

11. S Doosthi., et al. "Mosquito Surveillance and the First Record of the Invasive Mosquito Species Aedes (Stegomyia) albopictus (Skuse) (Diptera: Culicidae) in Southern Iran". Iran Journal of Public Health 45.8 (2016): 1064-1073.

12. MEETING REPORT. Expert meeting on Chikungunya modelling Stockholm (2008).

\section{Assets from publication with us}

- Prompt Acknowledgement after receiving the article

- Thorough Double blinded peer review

- Rapid Publication

- Issue of Publication Certificate

- High visibility of your Published work

Website: www.actascientific.com/

Submit Article: www.actascientific.com/submission.php

Email us: editor@actascientific.com

Contact us: +919182824667 